\title{
Preference for Church-Based Maternity Centers among Women Seeking Delivery Services in Akoko South West Local Government Area of Ondo State, Nigeria
}

\author{
Olugbenga Festus. Fabusiwa1, Adewale M. Adejugbagbe² \\ Olubankole Akinboboye ${ }^{3}$
}

\begin{abstract}
${ }^{1}$ Department of Medical Services \& Disease Control (MSDC); Ondo State Primary Health Care Development Board ${ }^{2}$ Department of Planning, Research and Statistics; Ondo State Primary Health Care Development Board

${ }^{3}$ Family Medicine, Federal Medical Center, Owo, Ondo State
\end{abstract}

Ondo State Primary Health Care Development Board

\begin{abstract}
We assessed preference for Church Based Maternity Centers (CBMCs) among women seeking delivery services in Akoko South West Local Government Area of Ondo State, Nigeria. Using a descriptive cross-sectional study, 420 consenting women attending 11 identified CBMCs at Akoko South West Local Government (ASLG) were interviewed with a pretested interviewer administered semi-structured questionnaire. The questionnaire was sectionalized into socio-demographic characteristics, perceived family support, pregnancy history and choice of delivery services. Data were analyzed and presented as frequency tables. The results shows that $52.8 \%$ of the respondents were age 30 years and above. More than one-third (46.6\%) of the respondents gave birth at the CBMCs at last delivery and 35\% preferred it for their next delivery. Main reasons for preferring the CBMCs for delivery among the respondents include, "for prayers" (68.8\%), "is affordable" (31.8\%) and "is close to domain" $(28.4 \%)$. Problems reported by respondents to be associated with delivery services at CBMCs include, lack of health education (46\%), poor handling of labour (26\%) and late referral of complicated cases (22\%). Preference for Church Based Maternity Centers for delivery was high among the women, with significant proportion of them reporting spiritual assistance as the main reason for preferring this service point. Hence, efforts directed towards sensitizing women of reproductive age on the importance of delivery at the hospitals and on dangers of using unskilled birth attendants during delivery are recommended.
\end{abstract}

Keywords: Preference for delivery, Church Based Maternity Centers, Women of reproductive age

\section{Introduction}

Globally, approximately 830 women die each day from preventable pregnancy related causes and $99 \%$ of this mortality occurs in the developing countries with more than $50 \%$ in sub-Saharan Africa ${ }^{[1]}$. Worldwide, a total of 303000 women were estimated to die during and following pregnancy and childbirth at the end of 2015 with almost all of the mortality occurring in low-resource settings ${ }^{[2]}$. In developing countries, maternal mortality ratio in 2015 was estimated to be 239 per 100,000 live births compared to 12 per 100000 live births in developed countries.
In Nigeria, about 2300 under-five-year olds and 145 women of childbearing age are lost every single day $^{[3]}$. This makes the country the second largest contributor to the under-five and maternal mortality rate in the world. The mortality of newborn babies in Nigeria represents a quarter of the total number of mortality of children of under-five with majority of these occurring within the first week of life and mainly due to complications during pregnancy and delivery. Thus, reflecting the intimate link between newborn survival and quality of care.

This article is published under the terms of the Creative Commons Attribution License 4.0 Author(s) retain the copyright of this article. Publication rights with Alkhaer Publications. Published at: http://www.ijsciences.com/pub/issue/2016-03/

DOI: 10.18483/ijSci.943; Online ISSN: 2305-3925; Print ISSN: 2410-4477 
Among the key strategy to reducing maternal and neonatal deaths was the Millennium Development Goals (MDGs) adopted by the international community in 2000. Under the $5^{\text {th }}$ goal of the MDGs, countries committed to reducing maternal mortality by 3 quarter between 1990 and 2015. Hence, the number of maternal mortality has dropped by $43 \%$ between 1990 and $2015^{[1]}$. In developing countries such as those in the sub-Saharan Africa, a number of countries halved their levels of maternal mortality since 1990, including Asia and North Africa. Given that it is possible to accelerate the decline in maternal mortality, countries have now united behind a new target of reducing maternal mortality even further. Thus, the sustainable development goals (SDGs) was set up in 2015 and the third goal of the SDGs aimed at reducing the global maternal mortality ratio to less than 70 per 100,000 births, with no country having a maternal mortality rate of more than twice the global average.

Mortality among women often occurs as a result of complications during and following pregnancy and childbirth. Most of these complications develop during pregnancy and are preventable or treatable. Other complications may exist before pregnancy but are worsened during pregnancy, especially if not managed as part of the woman's care or by skilled birth attendants (SBAs). The major complications that account for nearly $75 \%$ of all maternal mortality include severe bleeding (mostly bleeding after childbirth), infections (usually after childbirth), high blood pressure during pregnancy (pre-eclampsia and eclampsia), complications from delivery and unsafe abortion. $^{4}$ In Nigeria, high proportion of maternal mortality rate could be attributed to these complications which could have been prevented with access to essential maternal and basic health care services. ${ }^{5,6}$ Thus, in a bid to further make delivery services more acceptable, and more likely to be without complications, the World Health Organization (WHO) presupposes that $62 \%$ of deliveries in the developing countries be attended to by skilled birth attendants ${ }^{[2]}$.

In developing countries such as Nigeria, the lack of relevant and quality delivery care is a major concern. Majority of women in these region do not attend antenatal care and high proportion of them patronizes the unskilled birth attendants such as the churchbased maternity centers (CBMCs) due to one reason or the other ${ }^{[7]}$. Data from previous studies found that as high as $44.3 \%$ and $50 \%$ of women in Nigeria uses the CBMCs for delivery ${ }^{[8,7]}$, and most of these women preferred this service point because of their cultural and religious beliefs ${ }^{[9]}$. The WHO (2001) reported that the effect of religion on women' societal position, and harmful beliefs and traditions relating to child birth accounts for the reasons most women patronize the CBMCs for delivery ${ }^{[10]}$. Other reasons reported in previous studies to have contributed to the high patronage of CBMCs among women in Nigeria include; cost, fear of spiritual attack, lack of confidentiality, proximity, satisfaction with services and attitude of health workers ${ }^{[8,11,12]}$.

Given by the fact that previous studies had reported that high proportion of women patronizes the CBMCs for delivery care; there is a need for regular audit of the services rendered by this service point and investigate the reasons why women preferred the CBMCs for delivery. This will enable the formulation of health policies that could improve maternal care services aimed at reducing maternal morbidity and mortality in Nigeria. This study aims to assess preference for CBMCs and reasons for preferring their services among women seeking delivery care in Akoko South West Local Government of Ondo State.

\section{Materials and Methods \\ Study area}

This study was conducted in Akoko Southwest local government area of Ondo State. The LGA is one of the eighteen LGAs of Ondo State. It is made up of six wards namely; Oka-Akoko, Akungba-Akoko, Supare-Akoko, Oba-Akoko and Etioro-Akoko. The LGA shares boundaries in the north with Akoko North-West LGA, in the south with Akoko South East LGA and Agba LGA of Kogi State, in the west by Owo LGA and in the east by Emure LGA in Ekiti State. It has an approximate total population of 250,766 according to the 2006 population census and comprises mainly of the Yoruba ethnic group and other minor ethnic groups such as Ebira, Igala and Igbo. The people in this LGA are mainly Christians and Muslims and they practice the farming occupation majorly. There are eleven CBMCs identified by the Public Health Co-ordinator in Akoko South-West LGA with an average of one and hundred and eighty-five (185) monthly deliveries taking place in these centers as at the period of the study.

\section{Study Design}

This is a descriptive cross-sectional study that was conducted between February and April, 2010.

\section{Study Population}

The study population consist of women attending Church Based Maternity Centers for delivery in Akoko South west LGA. Women residing in the study area and seen at the CBMCs were included in the study. Women that were ill during the course of the study and refused to consent were excluded respectively.

\section{Sampling Technique}

Systematic and simple random sampling techniques 
were used to select the respondents in this study. Using proportional allocation, respondents were selected in each of the eleven CBMCs to form a stratum. Thereafter, a systematic sampling technique was used to select the respondents in each stratum. The first participant in each stratum was chosen using simple random sampling method, subsequently, the next (Kth) respondents was selected until the sample size was reached. The $\mathrm{K}$ factor was derived from the formula $\mathrm{K}=\mathrm{N} / \mathrm{n}$, where $\mathrm{N}$ is the total number of respondents in each of the centers and $\mathrm{n}$ is the total respondents selected in each stratum to meet up the sample size.

\section{Data collection}

A pretested interviewer administered semi-structured questionnaire was used to interview the respondents. The questionnaire was sectionalized into sociodemographic characteristics, perceived family support, pregnancy history and choices of delivery services. The perceived family support was extracted from the Perceived Social Support-Family Scale $(\mathrm{PSS})^{[13]}$. Oyedeji (1985) criteria were as well used for the social classification of respondents ${ }^{[13]}$.

\section{Data analysis}

The PSS is a 20-item validated measure of social support was used to determine the degree to which respondents perceived how their supports are fulfilled by family. Participants responded "yes", "no" and "Don't know" to each of the questions on perceived family support and a point was allocated to respondents that responded to yes, while other responses were scored zero. For reversed questions, "no" response was assigned a point. The scores were sum up with possible ranges of scores between zero and twenty. Higher score indicated higher family support (respondents with scores equal to or greater than average were categorized among those with strong family support, while those with scores 7 to 10 were categorized as weak family support and those with scores equal to or less than 6 were also categorized as those with no family support). Total income was calculated by adding the respondents' income from all sources.

Data were entered and analysed using Statistical Package for Social Sciences (SPSS) version 15. and a computer Programs for Epidemiological Analysis (CPEA).Categorical data was presented as frequency tables.

Ethical approval for the study was obtained from the Ethical Committee of Federal Medical Center, Owo, Ondo State, Nigeria. Approval for the conduct of the study was sought from the management of Akoko South West LGA while written informed consent was obtained from both the identified CBMCs and each pregnant woman.

\section{Results}

A total of four hundred and twenty (420) women were interviewed. As shown in Table 1, 52.8\% of the respondents were age 30 years and above. Majority $(69 \%)$ of the respondents were married and $31.9 \%$ were traders followed by civil servants $(24 \%)$. More than half $(58 \%)$ of the respondents had secondary level of education and $29 \%$ had tertiary. Most $(85 \%)$ of the respondents were Christians and $88.6 \%$ were from the Yoruba ethnic group. 
Preference for Church-Based Maternity Centers among Women Seeking Delivery Services in Akoko South West Local Government Area of Ondo State, Nigeria

Table 1: Socio-Demographic distribution of respondents

\begin{tabular}{|c|c|c|}
\hline Variables & Frequency $(n=420)$ & Percentage (\%) \\
\hline \multicolumn{3}{|l|}{ Age group(years) } \\
\hline $15-19$ & 32 & 7.6 \\
\hline $20-24$ & 64 & 15.2 \\
\hline $25-29$ & 102 & 24.3 \\
\hline $30-34$ & 119 & 28.3 \\
\hline $35-39$ & 58 & 13.8 \\
\hline $40+$ & 45 & 10.7 \\
\hline \multicolumn{3}{|l|}{ Marital Status } \\
\hline Married & 290 & 69.0 \\
\hline Un-married & 119 & 28.3 \\
\hline Divorced/Separated & 11 & 2.6 \\
\hline \multicolumn{3}{|l|}{ Occupation } \\
\hline House wife & 73 & 17.4 \\
\hline Trader & 134 & 31.9 \\
\hline Un-employed & 62 & 14.8 \\
\hline Student & 50 & 11.9 \\
\hline Civil-servant & 101 & 24.0 \\
\hline \multicolumn{3}{|l|}{ Educational level } \\
\hline Primary & 47 & 11.2 \\
\hline Secondary & 244 & 58.1 \\
\hline Tertiary & 122 & 29.0 \\
\hline Illiterate & 7 & 1.7 \\
\hline \multicolumn{3}{|l|}{ Religion } \\
\hline Christian & 357 & 85.0 \\
\hline Muslim & 56 & 13.3 \\
\hline Traditional religion & 7 & 1.7 \\
\hline \multicolumn{3}{|l|}{ Ethnicity } \\
\hline Hausa & 16 & 3.8 \\
\hline Igbo & 28 & 6.7 \\
\hline Yoruba & 372 & 88.6 \\
\hline Others & 4 & 1.0 \\
\hline Total & 420 & 100.0 \\
\hline
\end{tabular}

Socio-Economic Characteristics of Respondents

Table 2 shows the socio-economic distribution of the respondents. One hundred and forty-eight (35.2\%) of the respondents earns between 20,000 and 29,000 naira monthly respectively between 20,000 and
29,000 naira. More than a tenth $(15 \%)$ of the respondents spends more than 100 naira per each visit to the CBMC. Close to half (44\%) of the respondents were in the fourth social class followed by those in the third social class (35\%). 
Preference for Church-Based Maternity Centers among Women Seeking Delivery Services in Akoko South West Local Government Area of Ondo State, Nigeria

Table 2: Socio-economic characteristics of respondents

\begin{tabular}{lll}
\hline Variables & Frequency & Percentage \\
\hline Estimate of monthly income & 44 & \\
Less or equal N10,000 & 132 & 10.5 \\
N10001-19000 & 148 & 31.4 \\
N20000-29000 & 73 & 35.2 \\
N30000-39000 & 23 & 17.4 \\
N40000 \& above & & 5.5 \\
Other Sources of Income & 183 & \\
Friend & 198 & 43.6 \\
Club & 39 & 47.1 \\
Religious home & & 9.3 \\
Cost of Transportation & 266 & \\
<N100 & 47 & 63.3 \\
N100-199 & 16 & 11.2 \\
N200+ & 91 & 3.8 \\
Not indicated & & 21.7 \\
Social Class & 19 & \\
Social class 1 & 49 & 4.5 \\
Social class 2 & 147 & 11.7 \\
Social class 3 & 185 & 35.0 \\
Social class 4 & 20 & 44.0 \\
Social class 5 & & 4.8 \\
Total & $\mathbf{4 2 0}$ & $\mathbf{1 0 0 . 0}$ \\
\hline
\end{tabular}

Past and Current Pregnancy History of Respondents

In table $3,65 \%$ of the respondents had between 1-3 children. More than a quarter (46.6\%) of the respondents delivered at the $\mathrm{CBMC}$ followed by the government health facilities (42.1\%). More than half $(59.8 \%)$ of the respondents had complications during pregnancy. Among those that experienced complications during pregnancy, $57.3 \%$ had infection such as malaria, abdominal pain $(29.8 \%)$ and vaginal bleeding (12.7\%). Close to half $(44.7 \%)$ of the respondents experienced retained placenta among the complications experienced during past delivery followed by difficult delivery $(30.5 \%)$

Table 3: Past and current Pregnancy History of respondents

\begin{tabular}{|c|c|c|}
\hline Variables & Frequency $n=420$ & Percentage \\
\hline \multicolumn{3}{|l|}{ Parity (420) } \\
\hline 0 & 68 & 21.9 \\
\hline $1-3$ & 273 & 65.0 \\
\hline $4+$ & 55 & 13.1 \\
\hline \multicolumn{3}{|l|}{ Month of visit at CBMC } \\
\hline 1st trimester & 169 & 40.2 \\
\hline 2nd trimester & 245 & 58.3 \\
\hline 3rd trimester & 6 & 1.4 \\
\hline \multicolumn{3}{|l|}{ Place of Past Delivery } \\
\hline Government health facility & 148 & 42.1 \\
\hline Church-based Maternity centre & 164 & 46.6 \\
\hline Home & 28 & 7.9 \\
\hline Traditional birth Attendant centre & 12 & 3.40 \\
\hline Not indicated(including primigravida) & 68 & 16.2 \\
\hline \multicolumn{3}{|l|}{ Any Problem in this Pregnancy } \\
\hline Yes & 251 & 59.8 \\
\hline No & 169 & 40.2 \\
\hline \multicolumn{3}{|l|}{ Problem during this $\operatorname{Pregnancy}(n=251)$} \\
\hline Vaginal bleeding & 32 & 12.7 \\
\hline Abdominal pain & 75 & 29.8 \\
\hline Infection(malaria) & 144 & 57.3 \\
\hline \multicolumn{3}{|c|}{ Problem Experienced during past delivery $(n=131)$} \\
\hline \multicolumn{3}{|c|}{ Hemorrhage } \\
\hline Retained placenta & 33 & 25.1 \\
\hline \multirow[t]{2}{*}{ Difficult delivery } & 58 & 44.7 \\
\hline & 40 & 30.5 \\
\hline
\end{tabular}




\section{Preference for church-based maternity centers} among respondents

In table $4,61.7 \%$ of the respondents did ultrasound during ANC and $34 \%$ of them reported such only once during pregnancy. Reasons respondents did not had any ultrasound during pregnancy include, lack of request $(27.1 \%)$, followed by no money $(8.3 \%)$. Majority (84.8\%) of the respondents preferred to attend the CBMC for the next ANC and delivery, and $73.1 \%$ of them reported spiritual support inform of prayers as the main reason for preferring this service point, followed by reduced cost (6.7\%) and closeness to domain $(5.0 \%)$. Majority $(74.0 \%)$ of the respondents reported to be satisfied with the services of the CBMCs. Among respondents [64(15.2\%)] that reported that they were not willing to attend their next ANC and delivery at CBMC, $37.5 \%$ and $31.3 \%$ reported late referrer of complicated cases and no health talks as the main reasons.

Table 4: Antenatal care attendance and preference for church based maternity center among respondents

\begin{tabular}{lll}
\hline Variables & $\begin{array}{c}\text { Frequency } \\
\text { N=420 }\end{array}$ & Percentage (\%) \\
\hline Any Ultrasound during ANC(420) & 259 & 61.7 \\
Yes & 161 & 38.3 \\
No & & \\
Number of times Ultrasound was conducted during ANC (259) & 143 & 34.0 \\
Once & 94 & 22.4 \\
Twice & 22 & 5.2 \\
Many times & & \\
& 114 & 27.1 \\
Reasons ultrasound was not conducted during ANC (161) & 35 & 8.3 \\
No request & 12 & 2.9 \\
No money & & \\
Not accessible & 356 \\
Prefer to attend CBMCs for the next ANC and delivery (420) & 64 & 84.8 \\
Yes & & 15.2 \\
No & 307 & 73.1 \\
Reasons for attending ANC at CBMC (356) & 28 & 6.7 \\
Because we are being prayed for & 21 & 5.0 \\
It is cheap & & \\
Closeness to domain & & 31.3 \\
Reasons for not attending ANC at CBMC (64) & 20 & 21.9 \\
No health talk & 14 & 37.5 \\
Poor handling of antenatal cases & 24 & 9.3 \\
Late referrer of complicated cases & 6 & 20.7 \\
Le confidentiality & & 74.0 \\
Very satisfied & & 5.2 \\
Satisfied & 87 & 311 \\
Not satisfied & 22 & \\
\hline
\end{tabular}

\section{Discussions}

The predominant age range of women in this study was 25-34 years $(52.6 \%)$, this age group represents the peak period of their reproductive performance. The age group is similar to those obtained in previous studies among women seeking delivery care in CBMCs in Akwa-Ibom and Cross-river states ${ }^{[11]}$, and Ilesha, Osun state, Nigeria ${ }^{[14]}$. Majority of the respondents in this study have secondary or higher education. This might be connected to the fact that, in Ondo State, Nigeria, majority of the occupants in the LGA studied had been benefiting from free-education up to secondary school level for many decades, this must have afforded the respondents the opportunity to benefit and complete the secondary level of education. Furthermore, majority of the respondents were from the Yoruba ethnic group and which is understandable due to the fact that the study area is located in Yoruba land. Also, more than half of the respondents were married which may indicate some degree of family support. More than a quarter of the respondents in this study had problems in their past deliveries, which ranges from hemorrhage, retained placenta to difficult delivery. These respondents constituted high risk group that suppose not to access delivery services at CBMC where basic obstetric care are not readily available.

It is of interest to note that, about half halve (46.6\%) of the respondents had their last delivery at the CBMCs while just $35.2 \%$ delivered at the government health facility. This indicates that there is exodus of respondents to the CBMCs to seek delivery care. This may be because of rapid proliferation of churches that abound in most part of Nigeria of which the study area is not an exception. Furthermore, the proportion of respondents that attended the government health facility in this study is far below the WHO recommendation that $62 \%$ of deliveries in developing countries be attended to by 
skilled birth attendants ${ }^{[15]}$.

Majority of the respondents in this study preferred the CBMCs for ANC and delivery, with many preferring to attend the centers because of the spiritual support given by this service point in terms of prayers. Similar to this study, more than one-third of women in a study in Calabar, Nigeria patronizes the CBMC because of spiritual protection against satanic attack and faith in God (prayers) ${ }^{[11]}$. Prayer, which is an act of having inter-personal relationship with God, but in the case of pregnant woman, she is standing as an intercessor for the foetus(es). However, many of the respondents might have allowed their religious believes to take over many aspects of their social responsibilities; this may be because of poverty. Other reasons respondents preferred the CBMCs include closeness of the centers to their domain or place of abode. This result is in line with similar study conducted by Ogunlesi (2005) where more than half of the respondents opted for their place of delivery care because of convenience in term of distance to their homes ${ }^{[14]}$. Similar study, conducted by Michele on childbearing in Ghana revealed that proximity of delivery care center to women's residency seemed to be the largest determining factor of where the women receives their delivery care ${ }^{[16]}$. However, contrast to these study findings, previous study in Tanzania revealed that physical accessibility of health facility does not necessarily translate to increased utilization for delivery care particularly in areas where a mix of socio-cultural, personal and health service facility stand as barrier ${ }^{[17]}$.

In this study, more than two-third $(74.9 \%)$ of the respondents were satisfied with the services rendered at CBMC. Similar result was found in a study in Ilorin, Kwara State where $64 \%$ women reported to be satisfied with church based services. ${ }^{18}$

On the reasons why some respondents declined to attend the CBMCs for their next ANC and delivery, more than a quarter of the respondents considered no health education during their visit/prayer meetings. This was expected because, the service providers at the CBMC may not have been trained formally in the art of orthodox medicine, so they are not expected to have adequate knowledge on child delivery care. Similar observation has been made in previous study ${ }^{[18]}$. Other reasons some of the respondents declined using the CBMCs for next delivery include, poor handling of labour and late referral of complicated cases. This may be the reason why the outcome of deliveries at CBMCs in terms of complication like, birth asphyxia, birth trauma and maternal/perinatal mortality seem to be worse when compared to outcome of deliveries in other birthing places ${ }^{[19]}$. This is study findings corroborated that of
Udoma et al (2003) which revealed that, poor knowledge of risk factors, poor obstetric practices and refusal to refer patients when complications develop are major problems encountered at the $\mathrm{CBMCs}^{[11]}$.

\section{Conclusion}

Preference for Church Based Maternity Centers remains high among women seeking delivery care in Akoko west LGA, Ondo State. Reasons respondents preferred this service point were related mainly to spiritual assistants and ability to afford services. Hence, there is a need to sensitize the mothers on potential dangers of delivery at the CBMCs. Also, effective implementation of poverty alleviation programme is imperative and National Health Insurance Scheme should be accelerated to cover the entire population to reduce the problems of affordability and accessibility of quality delivery services at the hospitals.

Competing interest: Authors have declared that no competing interests exist.

\section{Authors' Contributions}

All the authors were involved throughout the course of the study. Olugbenga Fabusiwa designed the study. Analysis of the study and initial draft of the manuscript was done by Olugbenga Fabusiwa and Adewale Adejugbagbe and approved by all authors.

\section{References}

1) World Health Organization. Maternal Mortality. Available at: http://www.who.int/mediacentre/factsheets/fs348/en/. Lat accessed on $12^{\text {th }}$ December, 2015.

2) World Health Organization. Making Pregnancy Safer. Clinical role of the skilled birth attendant. Available at http://www.who.mt/making-

pregnancysafer/documents/92415916692/en/index.html. Last accessed on 12th December, 2015.

3) UNICEF. Maternal and child health. Available at: http://www.unicef.org/nigeria/children_1926.html. Last accessed on 12/30/2015. Last accessed on 12th December, 2015.

4) Say L, Chou D, Gemmill A, et al. Global Causes of Maternal Death: A WHO Systematic Analysis. Lancet Global Health.2014; 2(6): e323-e333.

5) Sweidan, M; Mahfoud, Z. And Dejong. "Hospital policies and practices concerning normal childbirth in Jordan". Studies in Family Planning, 2008. 39(1). 59-68.

6) UNICEF. The state of the world's children 2009. New York: United Nations Children's Fund.

7) Adetunji JA. Church-Based Obstetric care in a Yoruba community, Nigeria. Social Science and Medicine, 1992; 35 (9): 1171.

8) Etuk SJ., Itam IH., Asuquo EE. Role of spiritual church in antenatal clinic in Calabar, Nigeria. Nigeria Journal of Clinical Practice; 2008. 11 (2): 100-3.

9) Nwokocha, E.E.; O. Obono and A.A. Adedimeji. "Sociocultural Factors Affecting Pregnancy Outcomes among the Ibani of Rivers State, Nigeria”. Ibadan Journal of the Social Sciences, 2007. 5(1)

10) WHO (Federal Ministry of Health). Reduce maternal and Newborn Death in Nigeria: Make pregnancy safer 2001.

11) Udoma EJ., John ME., Udoze GE et al. Obstetric practices in 
spiritual churches in the South eastern Nigeria. Mary Slessor Medical Journal 2003. 3 (2):51-56.

12) Lo SV., Kaul S., Kaul R. et al. Teenage pregnancy: Contraceptive use and non-use. British Journal of Farm Plan 1994; 20:79-83.

13) Oyedeji GA. Socio-economic and cultural background of hospitalized children in Ilesha, Nigerian Journal of Paedistrics, 1984; 12 (4): 111-117.

14) Ogunlesi TA. The pattern of Utilization of prenatal and delivery services in Ilesa, Nigeria. The internet J. of epidemiology, 2005. 2 (2). 1-5.

15) WHO. Making pregnancy safer. The African Journal of Medicine and Medical Sciences 2010. Clinical role of the skilled birth attendant. Accessed at: http://www.who.mt/making-

pregnancysafer/documents/92415916692/en/index.html.
16) Michelle. Childbearing in Ghana: How beliefs affect care Africa dispora collection 2002. Accessed at $\mathrm{http} /$ :digitalcollections.sit/African_dispora_ins/76.

17) Declare M., Rose M., Albrecht J. Effectiveness of community based safe motherhood promoters in improving the utilization of obstetric care. The case of mtwara rural district in Tanzania. BMC pregnancy and childbirth. 2010 10:14.

18) Balogun OR. Patient perception of quality of antenatal services in four selected health facility in Ilorin, Kwara State, Nigeria. Nig med practioner 2007, 51 (4): 80-84.

19) Etuk SJ., Itam IH., Asuquo EE. Role of spiritual churches in antenatal clinic default in Calabar, Nigeria. East Africa Med Journal, 1999. 639-64. 